\title{
Role of antituberculous therapy in Eales disease
}

\author{
Periyanayagi $\mathbf{M}^{1}$, Arthi $\mathbf{M}^{2}$, Rajakumari $M^{3}$ \\ ${ }^{1}$ Dr. M. Periyanayagi, Senior Assistant Professor, ${ }^{2}$ Dr. Arthi. M, Postgraduate, ${ }^{3}$ Dr. Rajakumari. M, Professor, all authors \\ are affiliated with Regional Institute of Ophthalmology Government Ophthalmic Hospital, Egmore, Chennai, Tamilnadu, \\ India.
}

Address for Correspondence: Dr. M. Periyanayagi, Email: m.periyanayagi@gmail.com

\begin{abstract}
Aim: To establish the role of Anti Tuberculous therapy (ATT) in Eales disease. Methods: This is a prospective study in which 15 patients with Eales disease of the age group 18- 40 years were included. This study was conducted from January 2014 to June 2016. In our study, all patients were previously treated with a full course of steroids and four patients were treated with Pan retinal photocoagulation for neovascularisation in addition to the steroid therapy but had recurrences of inflammation. All the above patients were treated with Category 1 Anti Tuberculous therapy and oral prednisolone in tapering doses. The patients were reviewed at 1 and 6 months while on ATT and for every 2 months for one year after completion of ATT. The presence or absence of active inflammation was assessed and the outcome was analyzed. Results: In our study, 11 patients had complete resolution of inflammation with ATT and showed no recurrence of inflammation during the follow up period of one year. Two patients developed neovascularisation and Pan retinal photocoagulation was given and was considered as non response to treatment. One patient developed vitreous hemorrhage. One patient had persistent inflammation and showed no resolution of inflammation while on ATT. Conclusion: With the above study we conclude that anti tuberculous therapy should be considered in patients with Eales disease with recurrent inflammation for preventing further recurrences and reducing ocular morbidity due to complications.
\end{abstract}

Keywords: Eales disease, Anti tuberculous therapy, Pan retinal photocoagulation.

\section{Introduction}

Eales' disease is an idiopathic inflammatory venous occlusion that primarily affects the peripheral retina of adults [1]. First described by the British ophthalmologist, Henry Eales, in 1880, is characterized by three overlapping stages of venous inflammation (vasculitis), occlusion and retinal neovascularisation.

The disease is characterised by haemorrhages associated with perivascular exudation along the veins. The venous changes may vary from dilatation and beading from one region to occlusion at another site [2]. Retinal changes include perivascular phlebitis, peripheral non-perfusion, and neovascularization. Though initially reported in the United Kingdom the disease is highly prevalent in the Indian subcontinent with an incidence of 1 in $135-150$ cases with a very

Manuscript received: $6^{\text {th }}$ January 2017

Reviewed: $13^{\text {th }}$ January 2017

Author Corrected: $20^{\text {th }}$ January 2017

Accepted for Publication: 28 $8^{\text {th }}$ January 2017 significant male preponderance. Visual loss is characteristically caused by bilateral recurrent vitreous hemorrhage and its sequel. The etiopathogenesis of Eales' disease to date has remained controversial and illunderstood [3]. Association with bacterial and parasitic organism infections have been implicated. Raised serum $\alpha$ globulin levels have been implicated by Prathap et al and raised serum $\alpha-1$ acid glycoprotein levels have been documented by Rangarajan et al there is an increased expression of VEGF in patients with Eales disease when compared to other causes of neovascularisation which leads to prominent neovascular proliferation and propensity for sever vitreous hemorrhages in patients with Eales disease. Gilbert in 1935 and Stock in 1937 demonstrated tubercle bacilli from ocular specimens in patients with eales disease. In 1924, Finoff conducted an experiment where he injected tubercle bacilli in 46 experimental animals out of which only one animal developed 
vasculitis. It is possible that patients with Eales disease donot carry the viable organism but carry the DNA or non viable organisms. The presence of a positive Mantoux test and old healed tuberculous lesion in the lungs led to the implication of tuberculoprotein hypersensitivity in Eales disease. There are studies which have demonstrated the presence of MPB64 gene of mycobacterium tuberculosis in the epiretinal membranes in patients with Eales disease and in enucleated eyeballs of patients with Eales disease [4,5]. Recent studies also conclude that there is a strong association between tuberculosis and the occlusive vasculitis of Eales disease. Therefore this study was conducted to establish the role of anti tuberculous therapy, if any, in Eales disease. The treatment options in Eales disease depends on the stage of the disease. Treatment with oral or periocular steroids is warranted in patients in the active periphlebitis stage. For patients

\section{Materials and Methods}

Subject Selection- The study included 15 patients diagnosed to have Eales disease who presented to the Uvea \& Retina Services of RIO-GOH from January 2015 to June 2016 after obtaining approval from the Institutional Ethical Committee. Informed consent was obtained from all patients. All patients had previously received full course of steroids but had recurrences of inflammation on stopping steroids. Four patients had also received laser photocoagulation for neovascularisation in addition but had recurrence of periphlebitis.

\section{Inclusion Criteria}

Patients aged 18 to 40 years.

* Patients with active retinal periphlebitis defined as perivascular sheathing, cuffing and pre-retinal exudation that was treated with steroids but had recurrences of inflammation.

* Patients who have undergone laser photocoagulation in the past but presented with recurrences of inflammation.

\section{Exclusion Criteria}

* Patients with vitreous hemorrhage.

* Patients who have undergone vitrectomy in the past.

* Patients with Diabetes mellitus type1 or type 2.

Procedure- Patients with Eales disease meeting the inclusion criteria were included in the prospective study. Informed consent was obtained from the patients.

All patients underwent a complete ophthalmological examination - uncorrected and Best Spectacle corrected visual acuity, intraocular pressure measurement with Goldmann applanation tonometry and a detailed anterior segment examination with a slit lamp. Fundus evaluation was done by slit lamp bio microscopy with a $+90 \mathrm{D}$ lens and indirect ophthalmoscopy. All patients underwent fundus fluorescein angiography to assess the capillary non perfusion areas and neovascularisation if any. Monitoring and follow up of patients was done by taking serial fundus photographs of patients using Kowa VX 10 along with routine fundus examinations.

A Pulmonologist opinion was obtained for all patients with Chest $\mathrm{X}$ ray and Tuberculin skin testing to rule out any evidence of pulmonary or extra pulmonary tuberculosis. Presence of inflammation was defined as active retinal periphlebitis characterised by perivascular sheathing, cuffing and preretinal exudation which was treated with steroids previously but had recurrence of inflammation [figure $1 \mathrm{~A}, \mathrm{~B}$. Our study group also included four patients who were 
previously treated with Pan Retinal Photocoagulation for neovascularisation due to Eales disease but presented with recurrence of inflammation [figure 2]. All patients were started on Category-1 Anti Tuberculous Therapy which consisted of four drugs - Isoniazid, Ethambutol, Pyrazinamide and Rifampicin for first two months followed by Isoniazid and Rifampicin for the next four months. Patients were also started on oral prednisolone of $1 \mathrm{mg} / \mathrm{kg}$ body weight which was tapered and stopped over duration of six weeks. Resolution of perivascular sheathing and cuffing with or without sclerosed vessels or chorioretinal scars was considered as healed vasculitis.

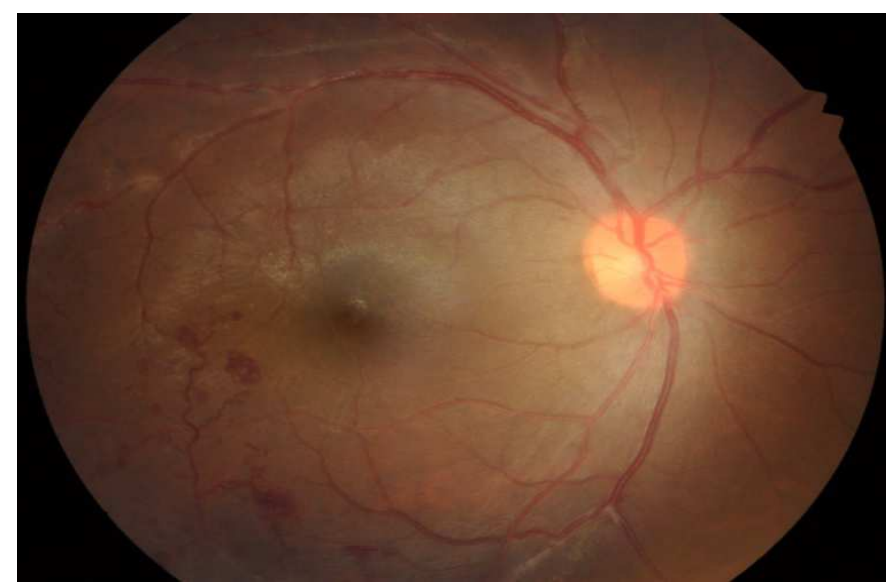

Figure-1a

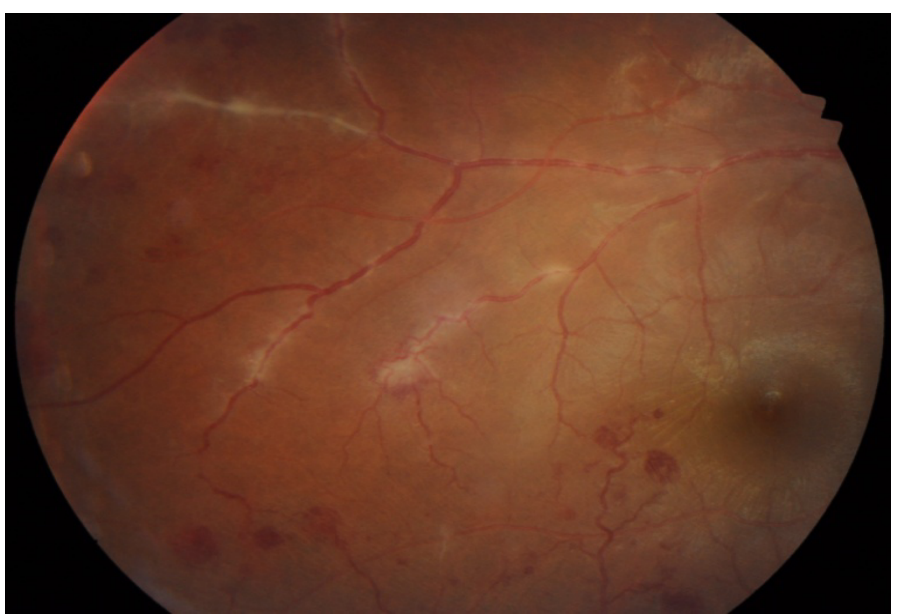

Figure-1 b

Figure-1(a,b) : Patient who presented with recurrent perivascular sheathing and superficial haemorrhages.

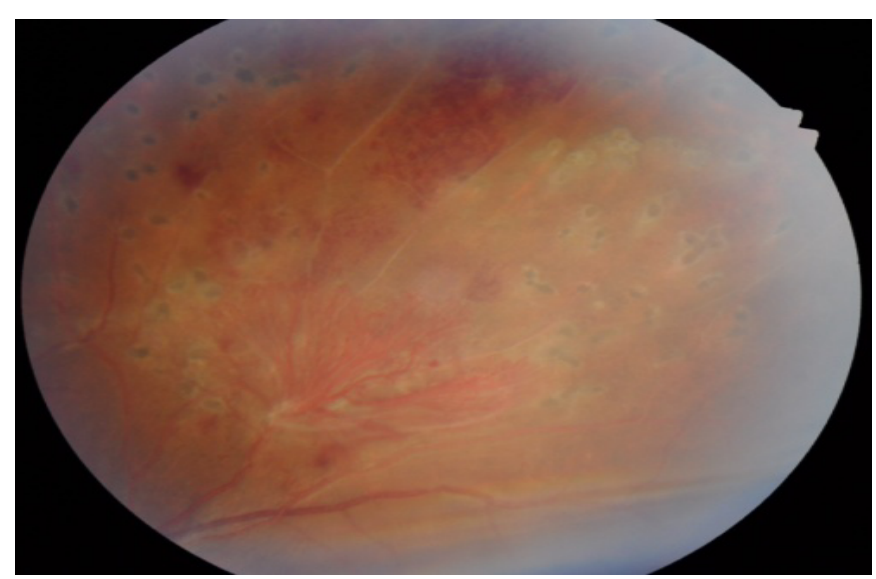

Figure-2: Recurrence of inflammation and neovascularisation in a patient following PRP and steroid treatment 
Follow Up- The Best Spectacle Corrected Visual Acuity and the presence and absence of inflammation were assessed at one and six months during the course of ATT. Patients were reviewed every two months of completion of ATT for a period of one year.

Detailed anterior segment examination with a slit lamp and fundus examination with slit lamp bio microscopy with $90 \mathrm{D}$ and indirect ophthalmoscopy was done during each visit.

\section{Results}

A total of 15 eyes of 15 patients were followed up and studied during a period of 18 months. Mean age of the study population was 24.8 years $($ Median $=24$ years, $\mathrm{IQR}=23$ ).

Table-1: Depicting the age group of our patients.

\begin{tabular}{|c|c|}
\hline Age Group (Years) & No of Patients \\
\hline $18-20$ & 2 \\
\hline $21-30$ & 12 \\
\hline $31-40$ & 1 \\
\hline
\end{tabular}

In our study, $80 \%$ of the patients belonged to the age group of $21-30 \mathrm{yrs}$. All patients included in the study were males. This conforms to the fact that Eales disease commonly occurs in young males. Among the 15 patients, Mantoux skin testing was strongly positive (>15 mm) for 5 patients, positive for 4 patients (10 $15 \mathrm{~mm}$ ) and negative for 6 patients $(<5 \mathrm{~mm})$. (Fig.5). the response to ATT and mantoux positivity was not statistically significant $(\mathrm{p}<0.05)$ [Table 1].

Table-2: Mantoux test results of our study population.

\begin{tabular}{|c|c|}
\hline Mantoux Test Result & No. of Patients \\
\hline Strongly Positive $(>15 \mathrm{~mm})$ & 5 \\
\hline Positive $(10-15 \mathrm{~mm})$ & 4 \\
\hline Negative & 6 \\
\hline
\end{tabular}

In all the 15 patients, there was no evidence of pulmonary or extra pulmonary tuberculosis.

During a follow up after six months of ATT, 11 patients showed signs of resolved vasculitis. Two patients of developed neovascularisation during the study and Pan retinal photocoagulation was given and was considered as non response to treatment. One patient had persistent inflammation even after completion of ATT. When the patients were reviewed after two months of completion of ATT, one patient had vitreous hemorrhage and was excluded from the study. The response to ATT in these patients was statistically significant $(\mathrm{p}<0.02)$. The improvement in best corrected visual acuity before and after ATT was not statistically significant $(\mathrm{p}<0.05)$

Table-3: Chi square showing that there is no association between mantoux positivity and response to treatment.

\begin{tabular}{|c|c|c|c|c|c|}
\hline & Value & Df & $\begin{array}{l}\text { Asymp. Sig. } \\
\text { (2-sided) }\end{array}$ & $\begin{array}{c}\text { Exact Sig. } \\
\text { (2-sided) }\end{array}$ & $\begin{array}{c}\text { Exact Sig. } \\
\text { (1-sided) }\end{array}$ \\
\hline Pearson Chi-Square & $1.111^{\mathrm{a}}$ & 1 & .292 & & \\
\hline Continuity Correction $^{\mathrm{b}}$ & .156 & 1 & .693 & & \\
\hline Likelihood Ratio & 1.095 & 1 & .295 & & \\
\hline Fisher's Exact Test & & & & .525 & .341 \\
\hline $\begin{array}{c}\text { Linear-by-Linear } \\
\text { Association }\end{array}$ & 1.037 & 1 & .309 & & \\
\hline $\mathrm{N}$ of Valid Cases & 15 & & & & \\
\hline \multicolumn{6}{|c|}{ a. 3 cells $(75.0 \%)$ have expected count less than 5 . The minimum expected count is 1.20 . } \\
\hline \multicolumn{6}{|c|}{ b. Computed only for a $2 \times 2$ table } \\
\hline
\end{tabular}




\section{Test Statistics}

\begin{tabular}{|c|c|}
\hline & Response \\
\hline Chi-Square & $5.400^{\mathrm{a}}$ \\
\hline Df & 1 \\
\hline p value & .020 \\
\hline \multicolumn{2}{|c|}{} \\
\hline \multicolumn{2}{|c|}{} \\
\hline
\end{tabular}

a. 0 cells $(0.0 \%)$ have expected frequencies less than 5 . The minimum expected cell frequency is 7.5.

\section{Discussion}

Eales disease is characterised by retinal periphlebitis of undetermined etiology which predominantly occurs young males and causes capillary non perfusion areas which proceeds to neovascularisation which culminates in vitreous hemorrhage thereby causing significant ocular morbidity in untreated cases. All the patients included in our study were males with a mean age of 24.8 years. The disease is usually bilateral. It is asymptomatic in the initial stages of perivasculitis and the patients usually develop symptoms only after the development of vitreous hemorrhage. Most common symptom is floaters or black spots, usually caused by vitreous hemorrhage followed by diminution of vision. Presence of a granulomatous anterior chamber reaction with a fundus picture resembling Eales disease points towards the diagnosis of sarcoidosis. Presence of an active or a healed choroiditis patch should also steer us to consider an alternative diagnosis of tuberculosis or syphilis.

The vascular findings include sclerosed vessels, pigmentation along the veins, kinking of veins and vessels proliferating towards the vitreous cavity. The healed periphlebitis may give an appearance of sheathing of vessels. Central Eales disease which is a variant of classical Eales is characterised by involvement of the posterior pole around the macula. Other rare macular involvement include epiretinal membrane formation or hemorrhage at the macula. Media haziness is usually due to recurrent vitreous hemorrhage and rarely due to vitritis. Advanced stages of the disease may develop fibrovascular proliferation leading to tractional retinal detachment. Rhegmatogenous detachments also commonly occur in the disease. These may be identified by $\mathrm{B}$ scan ultrasonography in the presence of an opaque media. Though Eales disease was first described as early as 1800 s the etiopathogenesis of the disease remained evasive. It was considered to be the manifestation of many diseases by Duke- Elder [7]. But recent studies indicate that Eales disease could not be differentiated from tuberculous occlusive vasculitis and anti tuberculous therapy with a short course of steroids should be considered for treatment in these patients [8]. In a study conducted by Madhavan et al demonstrated Mycobacterium tuberculosis genome in epiretinal membrane by nested PCR in 11 patients out of 23 in eyes removed from patients in Eales disease [6].

It has also been hypothesised that Eales disease can be due to a hypersensitivity to tubercular protein with many studies demonstrating a positive mantoux test in among $42-98 \%$ of patients with Eales disease. In our study $60 \%$ of the patients had a positive mantoux test. But the response to treatment was not determined by the mantoux result of the patient. This may be due to the fact that tuberculin skin testing does not differentiate active tuberculous infection from latent infection or a BCG vaccination.

Various neurological associations like spastic quadriplegia, internuclear ophthalmoplegia and multiple sclerosis have also been documented to be associated with Eales disease but none of the patients included in our study had such associations. Initiating anti tuberculous therapy in Eales disease is still controversial.

The study conducted to assess the response of patients with Eales disease to anti tuberculous therapy by Y R Sharma ET al in 2005 [8] did not foud any significant difference between the groups treated with Anti tuberculous therapy and steroids alone but the effect of anti tuberculous therapy on recurrence of inflammation and reduction of complications was not included in the study. Therefore this study was conducted to see if anti tuberculous therapy was effective in patients with Eales disease with recurrent episodes of inflammation though treated with steroids.

Our study demonstrated that anti tuberculous therapy is definitely effective in controlling the inflammation in 
patients with Eales disease and prevented recurrences. This response to treatment did not correlate with the mantoux status of the patient, as indicated in other studies which indicate that Eales disease occurs in mantoux negative patients as well [9].

The patients who responded to therapy during the follow up period did not develop any complications of neovascularisation, vitreous hemorrhage or tractional RD. These patients also did not have any recurrences of inflammation during the follow up period.

\section{References}

1. Spitznas M, Meyer-Schwickerath G, Stephan B. The clinical picture of Eales' disease. Albrecht Von Graefes Arch Klin Exp Ophthalmol. 1975;194(2):73-85.

2. Elliot AJ. Recurrent intraocular hemorrhage in young adults (Eales's disease); a report of thirty-one cases. Trans Am Ophthalmol Soc. 1954-1955;52:811-75.

3. Das T, Biswas J, Kumar A, Nagpal PN, Namperumalsamy P, Patnaik B, Tewari HK. Eales' disease. Indian J Ophthalmol. 1994 Mar;42(1):3-18.

4. Biswas J, Therese L, Madhavan HN. Use of polymerase chain reaction in detection of Mycobacterium tuberculosis complex DNA from vitreous sample of Eales' disease. British Journal of Ophthalmology. 1999 Aug 1; 8 3(8):994-.7. doi:10. 1136 /bjo. 83.8.994

5. Verma A, Biswas J, Dhanurekha L, Gayathri R, Therese KL. Detection of Mycobacterium tuberculosis with nested polymerase chain reaction analysis in enucleated eye ball in Eales' disease. International phthalmology. 2016 Jun 1;36(3):413-7.DOI: 10.1007/s 10792-015-0144-9.

\section{Funding: Nil, Conflict of interest: None. Permission of IRB: Yes}

\section{Conclusion}

Therefore anti tuberculous therapy can be considered in patients with Eales disease with recurrent episodes of inflammation along with a short course of oral steroids and it is effective in preventing complications and thereby reduces ocular morbidity in patients with Eales disease.

6. Madhavan HN, Therese KL, Gunisha P, Jayanthi U, Biswas J. Polymerase chain reaction for detection of Mycobacterium tuberculosis in epiretinal membrane in Eales' disease. Investigative ophthalmology \& visual science. 2000 Mar 1;41(3):822-5. doi:10.1007/s10792015-0144-9

7. Biswas J, Ravi RK, Naryanasamy A, Kulandai LT, Madhavan HN. Eales' disease-current concepts in diagnosis and management. Journal of ophthalmic inflammation and infection. 2013 Jan 14;3(1):1. DOI: 10. 1186/1869-5760-3-11.

8. Sharma Yog Raj, Krishana Kumar Ram, Tewari Hem Kumar, Rattan Ashok, Singh Deependra Vikram. Role of Antitubercular therapy in Eales' Disease. JK Science Journal of Medical Education and Research. 2005 OctDec;7(4): 208-211

9. Biswas J, Sharma T, Gopal L, Madhavan HN, Sulochana KN, Ramakrishnan S. Eales disease--an update.Surv Ophthalmol. 2002 May-Jun;47(3): 197-214.

\section{How to cite this article?}

Periyanayagi M, Arthi M, Rajakumari M. Role of antituberculous therapy in Eales disease. Int J Med Res Rev 2017;5(01):74-79. doi:10.17511/ijmrr. 2017.i01.11. 